which mark the surface of oblique fracture in a similar manner to those of the cleavage face. In fact, the appearances are remarkably similar to those of ausweichungsclivage, described by Heim in his "Gibergsbildung"; but the observations throw no light on the remarkable radiate form sometimes assumed by the structure. In a paper in the same journal Mr. Joly mentions that, in examining specimens of $O$, antiqua and $O$. radiata, he detected the following peculiarity: a sunken or depressed delineation of one form accompanied a raised or relieved delineation of the other form. Thus, if on any specimen O. antiqua appeared as a depression, on that same surface the $O$. radiata appeared in relief.

From this observation it appeared probable, if any meaning was to be attached to the relation, that a further

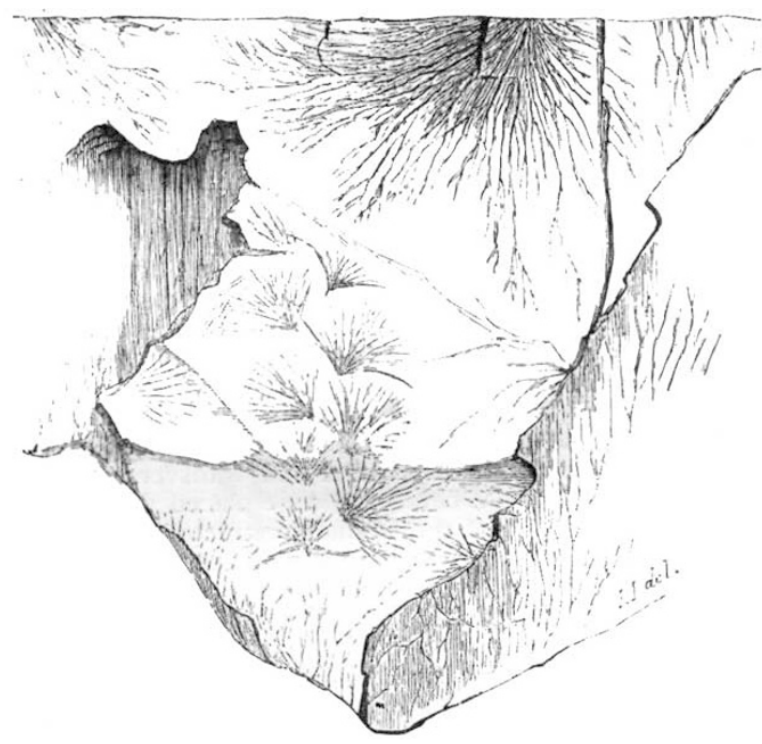

relation would be found to obtain between the mode of delineation and the position in the rock. This, a further examination revealed; in this order: on the upper surface, or what was most probably the surface of deposition (the cleavage of the Cambrian slate of Bray Head coincides generally with the plan of bedding), the $O$. radiata appeared invariably as a depression, the $O$. antiqua in relief.

When fragments were peeled off the slate, the marks were found to be transmitted, or extending to the layers beneath, so that lines on the upper are seen as continued on the adjacent lower layer, this, too, for thicknesses exceeding a millimetre. The accompanying woodcut recalls the appearance of a surface of rock in which this is fairly well shown.

\section{ON THE DISTRIBUTION OF TEMPERATURE} IN THE ANTARCTIC OCEAN

$\mathrm{T}$ the regions of the Antarctic Ocean where icebergs are numerous, and where in winter the sea-water freezes, the distribution of temperature in the deeper layers of water is peculiar. The facts are detailed in the "Challenger Narrative" (vol. i.). The general result of her observations went to show that, from the most southerly station, a wedge of cold water stretches northwards for more than $12^{\circ}$ of latitude, underlying and overlying strata at a higher temperature than itself (p. 418 ).

Although the conditions and facts likely to throw light

2 Abstract of a paper read by Mr. J. Y. Buchanan before the Royal Society of Edinburgh, March 21, r887. upon the cause of the existence of this cold intermediate or superficial stratum overlying water which at any rate in its upper layers has a temperature higher than that of freezing distilled water are discussed, no satisfactory explanation of the phenomenon is given. One important fact is noticed at page $42 \mathrm{I}$. "The fact that the cold wedge above referred to extended north just as far as the icebergs did in March 1874 points to there being some connexion between the temperature and the presence of melting icebergs." It is well known that icebergs consist of land-ice, which is as nearly as possible pure frozen water, and melts in the air at $32^{\circ} \mathrm{F}$. It was thought that the effect of immmersion of such a substance in a medium having a temperature $3^{\circ} \mathrm{F}$. lower than its melting-point would be to indefinitely preserve it, that in fact only the lower surfaces of the icebergs large enough to reach to a depth of 300 fathoms would suffer any melting at all. The existence of the cold stratum was ascribed wholly to the cold brine, separated from the ice on the freezing of the sea-water, sinking downwards with an initial temperature of from $28^{\circ} .5$ to $29^{\circ} \mathrm{F}$. This cause, though existing and in operation, is quite inadequate to produce the effect observed. In Dr. Otto Pettersson's admirable work "On the Properties of Water and Ice," undertaken in connexion with the work of the Vega Expedition, there is a footnote at page 318 where he says:"As a thermometer immersed in a mixture of snow and sea-water which is constantly stirred indicates $-\mathrm{I}^{\circ} .8 \mathrm{C}$., we may regard this as the upper limit of the freezing and the nether limit of the melting temperatures of sea-water." In a review of Dr. Pettersson's work in NATURE (vol. xxviii. p. 4I7) I expressed doubt of the accuracy of this observation, but on repeating it I found it to be confirmed. It affords a complete explanation of the cold wedge of water in the Antarctic Ocean and the dependence of its thickness on the range of icebergs. These enornous islands of ice, a a very large proportion of which rise in tabular form to a height of 200 to 300 feet above the sea, float in many cases with their lower surfaces at a depth of from 250 to 300 fathoms. The warmer and denser water coming from lower latitudes (see "Challenger Narr." vol. i. p. 428) bathes these lower surfaces, the temperature of the mixture at the surface of contact falls, the heat abstracted from the sea-water melts a corresponding amount of the ice of the iceberg, and a saline solution is produced, less salt and therefore lighter than the water away from contact with the iceberg, and having a temperature which depends immediately on the strength of the resulting solution. Being lighter than the surrounding water, this resulting solution necessarily flows up along the sides of the berg to the surface, and its place is taken by fresh undiluted sea-water which in its turn is cooled, diluted, and transferred to the surface. The result is the production of a most energetic engine of circulation and means of cooling and equalising the temperature of the water within the reach of icebergs. As there is continual renewal of the ocean water brought into contact with the ice, and as its composition is constant, the temperature produced is practically constant, namely $28^{\circ} .8$ to $29^{\circ} \circ \mathrm{F}$, , or $-I^{\circ} .7$ to $-\mathrm{I}^{\circ} .8 \mathrm{C}$. The layer of lighter water from 50 to 80 fathoms thick at the surface is due principally to this melting of land-ice, though it is also due in very small proportion to the melting of sea-ice.

Table giving the temperature at which ice melts in sea-water containing different percentages of chlorine

$\begin{array}{llllllll}\text { Temp. C. } & \ldots & \ldots & \mathrm{I}^{\circ} \mathrm{O} & \mathrm{I}^{\circ} \cdot \mathrm{I} & \mathrm{I}^{\circ} \cdot 2 & \mathrm{I}^{\circ} \cdot 3 & \mathrm{I}^{\circ} \cdot 4\end{array}$

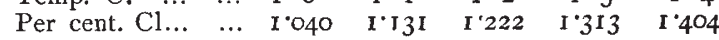

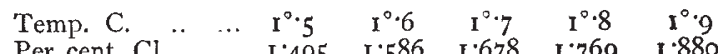

$\begin{array}{llllll}\text { Per cent. Cl... } \ldots & \text { I'495 I'586 } & \text { I'678 } & \text { I } 769 & \text { I.880 }\end{array}$

This table is taken from a paper on ice and brines, communicated to the Royal Society of Edinburgh on March 21, 1887. 
The density (at $15^{\circ} .56 \mathrm{C}$.) of the sea-water which comes in contact with the lower surfaces of the icebergs is I.0255, which represents a chlorine percentage of $I^{\circ} 90$. Ice actually melting in this water would produce a temperature of $-\mathrm{I}^{\circ} .92 \mathrm{C}$. When ice is immersed in this water it lowers its temperature, and a portion of the ice is melted, producing dilution. The concentration, therefore, or chlorine percentage, which will determine the melting temperature of the ice, will be a little lower than that of the original sea-water. From the Challenger observations we see that, on the confines of the pack-ice the cold stratum of water has a uniform temperature of $29^{\circ} \mathrm{F} .\left(-\mathrm{I}^{\circ} 67 \mathrm{C}\right.$. $)$. Ice melts at this temperature in sea-water containing $I^{\circ} 65$ per cent. of chlorine. In this process ice is melted, so that roo grammes pure warm sea-water become I 9 grammes of diluted cold sea-water. It will be observed that the ice which has been formed in the atmosphere at a temperature of $32^{\circ} \mathrm{F}$. comes in this way to be melted at a temperature of $29^{\circ} \mathrm{F}$.; and the pressure exerted by the 300 fathoms of sea-water, though it may assist in the lowering of the melting temperature, is insufficient to account for the amount.

\section{TO FIND THE DAY OF THE WEEK FOR ANY GIVEN DATE}

HAVING hit upon the following method of mentally computing the day of the week for any given date I send it you in the hope that it may interest some of your readers. I am not a rapid computer myself, and as I find my average time for doing any such question is about 20 seconds, I have little doubt that a rapid computer would not need I 5 .

Take the given date in 4 portions, viz. the number of centuries, the number of years over, the month, the day of the month.

Compute the following 4 items, adding each, when found, to the total of the previous items. When an item or total exceeds 7 , divide by 7 , and keep the remainder only.

The Century-Item.-For Old Style (which ended September 2, 1752) subtract from 18. For New Style (which began September 14) divide by 4 , take overplus from 3, multiply remainder by 2 .

The Year-Item.-Add together the number of dozens, the overplus, and the number of 4's in the overplus.

The Month-Item.-If it begins or ends with a vowel, subtract the number, denoting its place in the year, from Io. This, plus its number of days, gives the item for the following month. The item for January is " 0 "; for February or March (the 3rd month), "3"; for December (the I2th month), "12."

The Day-Item is the day of the month.

The total, thus reached, must be corrected, by deducting "I" (first adding 7, if the total be "O"), if the date be January or February in a Leap Year : remembering that every year, divisible by 4 , is a Leap Year, excepting only the century-years, in New Style, when the number of centuries is not so divisible (e.g. 1800).

The final result gives the day of the week, "o" meaning Sunday, "I" Monday, and so on.

\section{EXAMPLES}

I783, September I8

I7, divided by 4 , leaves "I " over; I from 3 gives " 2 "; twice 2 is " 4 ."

83 is 6 dozen and $1 \mathrm{I}$, giving 17 ; plus 2 gives 19 , i.e. (dividing by 7) " 5 ." Total 9, i.e. " 2 ."

The item for August is "8 from Io," i.e. " 2 "; so, for September, it is " 2 plus 3," i.e. "5." Total 7, i.e. "o," which goes out.

I 8 gives "4." Answer, "Thursday."
1676, February 23

16 from 18 gives " 2. ."

76 is 6 dozen and 4 , giving Io ; plus I gives I , i.e. " 4 ." Total " $6 . "$

The item for February is " 3." Total 9, i.e. "2."

23 gives " 2. ." Total " 4 ."

Correction for Leap Year gives " 3." Answer, "Weinesday." LEwIS CARROLL

\section{NOTES}

IN the Report submitted yesterday at Edinburgh to the halfyearly general meeting of the Scottish Meteorological Society, the Council state that the work at the Ben Nevis Observatory continues to be carried on by $\mathrm{Mr}$. Omond and the assistants in the same highly satisfactory manner as has been recorded in previous Reports. In addition to the laborious work of observing at all hours of the day and night, of reducing the observations, and forwarding copies for the Societv and the Meteorological Council, the staff of the Observatory has given very effective assistance in the preparation of the tables of the meteorology of Ben Nevis now in the press. Several interesting researches are being conducted at the Observatory, the results of which will be communicated to a future meeting. The Directors took steps last autumn to raise subscriptions to clear off the debt on the institution, and to establish a low-level station at Fort William, at which hourly observations may be made for comparison 'with those at the Observatory. It is only by two sets of observations at the top and bottom of the mountain that the Ben Nevis Observatory can be utilised, with the desired success, in the furtherance of meteorological science, but particularly in that branch of it which concerns the improvement of the system of forecasting the weather of the British Islands.

ON Tuesday evening last the Lord Advocate stated in the House of Commons that the Scottish Universities Bill would shortly be introduced.

The Paris Medical Faculty has decided to alter considerably the mode of competition for its Fellowships. The general object of the changes is to secure more original workers. The thesis (which has usually been the work, not of the candidate himself, but of his friends) is to be suppressed. Each candidate will henceforth have to deliver a lecture on his own scientific researches.

THE French Chamber of Deputies has decided that the buildings of the College of France shall be considerably enlarged. Fifty years ago, when this institution had only seventeen pro. fessors, its present buildings were sufficient; but now, when it has forty-one professors, they are very inadequate. It is to have four new lecture-rooms, a geological gallery, a set of rooms for other collections, a library, a meeting-room for professors, and eight laboratories. These additions will cost over 9,000,nno francs.

THE Anatomical Society, founded last September at Berlin, will hold its first general meeting at Leipzig on April 14. The Society has now over 170 members in England, Germany, Austria, Hungary, Switzerland, Holland, Belgium, Scandinavia, France, Russia, Italy, and North America.

DR. Hans ReuCH, who has lately devoted much time to the study of earthquakes in Norway, has issued a tabulated circular, which has been reproduced in the entire Norwegian Press, requesting that reports of any phenomena observed in connexion with earthquakes may be sent to him. By Government permission all such reports may be transmitted through the post free of charge. Dr. Reuch asks especially for information 